\title{
The Impact of Exercising on Bone Mineral Density in Women Exercising on Bone Mineral Density
}

\author{
Nilza Aparecida de Almeida Carvalho ${ }^{1 *}$, Simoni Bittar ${ }^{2}$, Bruna Eriko Matsuda Marangoni² and $^{3}$ \\ Cláudio Santili ${ }^{3}$ \\ ${ }^{1}$ Chief of Physical Therapy Department, Santa Casa de Misericórdia de São Paulo (SCMSP), São Paulo, Brazil \\ ${ }^{2}$ Physical Therapy Department, Santa Casa de Misericórdia de São Paulo (SCMSP), São Paulo, Brazil \\ ${ }^{3}$ Professor in the Orthopaedics and Traumatology Department, Santa Casa de Misericórdia de São Paulo (SCMSP), São Paulo, Brazil \\ ${ }^{3}$ Orthopaedics and Traumatology Department, Santa Casa de Misericórdia de São Paulo (SCMSP), Brazil
}

Received: July 01, 2014; Accepted: August 22, 2014; Published: August 23, 2014

*Corresponding author: Nilza Aparecida de Almeida Carvalho, Chief of Physical Therapy Department, Santa Casa de Misericórdia de São Paulo (SCMSP), Doutor Cesário Mota Junior st., 112, SP 01201-000, São Paulo, Brazil, Tel: 55-11-2176-1585; Fax: 2176-1585; E-mail: diegogalace@yahoo.com.br

\begin{abstract}
The reduction in Bone Mineral Density is important during the ageing process because it can be a potential manifestation of osteoporosis.
\end{abstract}

Aim: The objective was to assess the impact of exercise on bone mineral density in women.

Materials and Methods: This research was conducted under the supervision of a physical therapist focused on the bone mineral density of ageing women. One hundred women, 60 years of age or older, were included in the study and underwent bone mineral density evaluation before and after administering two types of exercise.

Results: Only $58.8 \%$ of the participants had undergone bone mineral density evaluation at some time before the study, and $74.4 \%$ were sedentary. No significant difference was found between vertebral and femoral bone mineral density before and after the intervention in both groups. No correlation was found between the evolution of bone mineral density and the age of menarche.

Conclusion: Exercise, with or without supervision, also helped to maintain bone mineral density in postmenopausal women, who would have a natural tendency to experience bone mineral density loss.

Keywords: Osteoporosis; Motor activity; Bone mineral density; Exercise; Muscle stretching exercises; Resistance training

\section{Introduction}

There has been a reduction in mortality and an increase in life expectancy that results in an ageing population and as a result in a rise in chronic and degenerative diseases, including osteoporosis [1,2]. A decrease in Bone Mineral Density (BMD) is particularly important in the ageing process due to the potential development of osteoporosis in both sexes [3-5]. Osteoporosis is an osteometabolic disorder characterized by a decrease in BMD, with a deterioration in bone micro architecture, leading to an increase in skeletal fragility and the risk of fractures $[3,5]$.
Osteoporosis is defined by having a T-score of -2.5 or lower on a Dual-energy X-ray Absorptiometry (DXA) test or scan $[4,6]$.

A drop in estrogen production, characteristic of the postmenopausal stage of life, is a factor that accelerates BMD reduction [7]. This means that women constitute a population that is especially susceptible to primary type I (or postmenopausal) osteoporosis [8,9]. In Brazil, 10\% of the female population live one third or more of their lives beyond menopause; healthcare in this population includes measures focused on behavioral change and long-term investment in health [9-11]. The prevention of this disease arouses a great deal of clinical interest, due to the continuing increase in the elderly population $[3,4,12]$. Among the aspects that are related to good quality of life in old age is good functionality.Elderly individuals have indicated this factor as one of the most important, since it is associated with independence and autonomy [13].

Recent advances in bone mass measurement techniques allow us to evaluate BMD with good accuracy, reproducibility, and a minimum exposure to radiation [10]. A diagnosis of osteoporosis is based upon BMD, and makes it possible to recognize the disease at an early stage, which can provide an opportunity for early intervention with preventive measures. Most studies have demonstrated a positive correlation between exercise levels and bone mass. However cross sectional studies demonstrate simply an association and do not imply causation, benefits have been reported in women, with low BMD who have taken part in strength training [14-16]. It is already well-recognized that resistance exercises (in individuals without nutritional impairment) can stimulate bone formation $[7,11,17]$. However, it is necessary to know whether the supervision of physical activity can produce effective evidence regarding the effect of exercise on bone quality.

\section{Objective}

The objective of this study was to analyze the effectiveness of supervised and non-supervised exercise training on loss of bone 
mineral density in postmenopausal women.

\section{Methods}

This was a prospective, clinical, randomized study. The women were selected for this study between February and July 2009 by the researchers (physiotherapists), and they were largely patients treated at general outpatient clinics, clinics with other specialties, or companions of patients under treatment, bacause this patientes was recruted by in a central hospital with multiply specialits which had treatment for osteoporosis. The protocol for admission in the study featured their identification, current age, age of menarche, weight, height and whether they performed physical activity prior to the study. When the subjects were 60 years of age or older and if they had not recently had a bone densitometry test (BMD), they were considered eligible. The researchers then asked whether the subjects wished to take part in a survey on osteoporosis and then advised them to await contact, if they were selected. No patients were using any special diet even drugs.

Initial data were gathered on 1,000 women and this data was entered in a spreadsheet for random calculation. A sample of one hundred subjects was arbitrarily chosen for the study. Informed consent was obtained from all the participants, and the study was approved by the institutional review board. The 100 women selected were contacted by phone by the researchers asking them to come to the clinic for a physical assessment. Physiother Physiotherapeutic anamnesis was executed apeutic anamnesis was executed and a physician (CS) requested the BMD test. Of the 100 women contacted, 82 turned up for assessment. They all agreed to take the BMD test at the institution, and after receiving guidance, the researchers developed the physical activity program proposed in this study.

The following exclusion criteria constituted the study:

- Failure to agree to sign the informed consent form;

- Alterations of cardiac function diagnosed previously, such as arrhythmia, heart attack and others;

- A history of fracture (vertebrae, femur, radius, etc) reported by the women themselves;

- Cardiorespiratory and/or musculoskeletal diseases that would preclude the practice of physical activity; and

- Continuous use of corticosteroids for treatment of chronic disease.

Anamnesis was performed during the initial interview by a physiotherapist (NAC) that consisted of demographic and clinical items, such as age, body weight, height, race, education, comorbidities (mainly cardiac problems, which are exclusion factors), age at first menstruation and at menopause, whether the patient had been exercising regularly in the last few months, and whether the subject had ever had a BMD test at any time. The BMD test was conducted on the same day of the anamnesis, by a professional medical doctor who was specialized in BMD , in a pilot study 10 patients were evaluated and reevaluated, with ICC value 0.87 , and after 10 days, the patients returned for receipt of the results, which were used to build a database. With all the assessments performed and with all the results calculated for the first BMD, the women were divided into manual and supervision subgroups by a quasi-random method, i.e., the first patient was included in one group, the following patient in the other, and so on.

The first subgroup, called manual, included 42 patients, who received training and information regarding the importance of physical activity. Guidance was provided in the form of an illustrative manual regarding the quantity, type and intensity of exercises. The manual, created by the researchers for this study, contained information on osteoporosis (definitions and how it is possible to prevent it), guidance and frequency concerning how to perform the exercises 2-3 times per week at home, for nine months. The women were interviewed by telephone by the same researcher every three months, to clarify queries regarding the execution of the exercises, and to verify whether they were performing the exercises at the correct frequency.

The second subgroup, called supervision, included 40 women who performed physical activity twice a week, in sessions lasting for one hour each, for nine months, within the physiotherapy Sector of Santa Casa de Misericórdia de São Paulo (SCMSP). The sessions for the practice of exercises were supervised by two collaborating physiotherapists. The participants were subdivided into 4 groups each containing 10 women, and their presence was controlled by an attendance card.

Participants from both groups received training and counseling on the importance of physical activity and its relationship to ageing, the risks of falls, the importance of using closed-toe shoes, preferably without heels, and daily postural guidance during these activities. BMD tests were performed on all the participants at the baseline (before the beginning of the program) and at the end (after nine months) of the study. All the tests were carried out using the same equipment (Model 8743, Prodigy Advance, General Electric) and evaluated by the same professional.

In this study, we used the criteria from the World Health Organization for the diagnosis of osteoporosis. BMD from 1 to 2.5 Standard Deviations (SD) below the reference was designated as osteopenia, and BMD more than 2.5 SD below the reference was designated as osteoporosis. As a rule, for each SD below the reference, the risk of fractures doubles [3]. The results of the bone densitometry test are presented by means of absolute values ( $\mathrm{g} /$ $\mathrm{cm}^{2}$ ). Some results were considered as normal at the conclusion of the test, except in cases where there was the presence of low bone mass (or osteopenia) or osteoporosis. The evolution of BMD was obtained through the comparative difference between the first and the second BMD, observing gain, maintenance or loss of bone mass by absolute values $\left(\mathrm{g} / \mathrm{cm}^{3}\right)$ and normal BMD values, low bone mass or osteoporosis at the conclusion of the research. The physical activity program was composed of one-hour sessions: 10 minutes of stretching exercises of the Upper Limbs (UL), Lower Limbs (LL) and trunk; 20 minutes of aerobic exercises on the treadmill and/or stationary bicycle and/ or walking associated with free active UL and LL exercises; 20 
minutes of progressive resistance training for UL and LL, with the use of dumbbells and ankle weights; and 10 minutes of play activities with a ball and a relaxation session (massage).

For the qualitative variables, we presented tables of absolute and relative frequency and contingency tables. For the quantitative variables, we calculated summary measures and built boxplot graphs. To verify whether the groups were homogeneous in terms of demographic characteristics (ages, weight, height, for example), we conducted the Student's t-test. We calculated a Confidence Interval of 95\% (CI 95\%) of the mean variations of the bone densitometry to verify Post vs Pre evolution. To verify whether some variables (age, age of menarche, age and time of menopause, weight and height) influenced the results of the densitometry, we calculated Pearson's correlation coefficient (and built scatter graphs). The comparison of the values obtained from the bone densitometry test between the performance or non-performance of physical activity was made through the Mann-Whitney test. The comparison between the manual and supervision groups in relation to race, performance of previous densitometry and the practice of previous physical activity was made by means of the chi-squared test. This test compares the proportions of the variables mentioned in relation to the two groups.

Because the results of the densitometry are also provided in categorized form (normal, low bone mass or osteoporosis), we verified the Post vs Pre evolution of the patients through the mcnemar test. This test is used to compare paired categorized data. The significance level adopted was 5\% (0.05). We used version 13.0 of the SPSS (Statistical Package for Social Sciences) software.

\section{Results}

Among the women evaluated, only $58.8 \%$ had undergone a bone densitometry test before. Most patients (74.4\%) did not engage in physical activity before the intervention. The patients' overall mean age was 70.68 years old, with 70.25 years of age in the supervision group (Standard Deviation, SD: 6.10; variation of 60-86 years) and 71.12 years of age (SD: 5.81; 61-87 years) in the manual group. When we compared the groups with one another in relation to age, age at menarche and menopause, weight and height, we observed that there was no statistically significant difference between the groups ( $p>0.3)$.

There was no significant difference in BMI (Body Mass Index) between the groups. The patients from the manual group were, on average, 13.10 years of age at menarche (SD 1.48 variation of 11 to 17 years). In relation to the manual group, the mean age was 12.74 years (SD: $1.68 ; 9-17$ years). The age of menarche of the two groups was similar $(p=0.602)$. In the supervision group, the average age of menopause was 47.45 years (SD: 6.24), while in the manual group, the average age was 48.29 years (SD: 4.98). The comparison of menopause age between the two groups was not statistically significant ( $p=0.124)$. In relation to the mean participation in physical activity of the supervision group, 13 patients had a presence of $90-100 \%, 4$ at $80-90 \%, 5$ at $70-80 \%$, 8 at $60-70 \%$ and 9 at $50-60 \%$. The manual group was advised to exercise three times a week over a period of nine months. Before the interventions, only $17.1 \%$ of the women presented normal BMD test, $58.8 \%$ had low bone mass and $24.4 \%$ presented osteoporosis.

No statistically significant difference was observed in the BMD of the lumbar spine, femoral neck and total femur before and after the intervention in the supervision and manual groups. This difference does not occur when we compare both groups by means of the Student's t-test, with $\mathrm{P}=0.719,0.442$, and 0.714 , respectively of the lumbar spine, total femur, and femoral neck (Table 1). Table 2 presents summarized group measurements of the variation of the bone densitometry (pre-post) after interventions, and during manual and physical activity. It is evident through the Pearson's correlation coefficient $(0.152$; $-0.026 ; 0.008)$, that when analyzing a possible correlation among the evolutions of the BMDs of the lumbar spine, total femur, and femoral neck within the menopause time, respectively, there was no correlation among them. There was no difference among the evolutions of BMD of the lumbar spine, total femur, and femoral neck in relation to prior physical activity. The values $P$ and $95 \%$ of CI are presented in Table 3.

In Table 4, we can observe that there was no correlation between age, age of menarche, age of menopause, weight and height when compared to the evolutions between the differences of the BMDs.

In Tables 5 and 6, we can observe the comparison of the results of the BMDs before and after the intervention in the manual and supervision groups as analyzed by means of the mcnemar test, with P values $=0.079$ and 0.004 , respectively.

Through direct clinical observations and testimonials from the participants of the supervision group, the patients felt more "malleable" (flexible), in better form, slept better, reported weight loss, no longer felt tired when walking or going up and down stairs, had begun to correct their postures during their daily activities, and also reported that they felt more willing to engage with other people, and they were enthusiastic about going out for walks. All the patients from this group reported that they intended to look for another public place to continue with their physical activities. The patients from the manual group were

Table 1: Comparison of the results of the evolutions of lumbar vertebrae, total hip and femoral neck Bone Mineral Density (BMD) between the groups using the Student's t-test

\begin{tabular}{|c|c|c|c|c|c|}
\hline BMD $^{+}$ & Group & $\mathbf{N}$ & Mean & $\begin{array}{c}\text { Standard devia- } \\
\text { tion }\end{array}$ & $\mathbf{P}$ \\
\hline \multirow[b]{2}{*}{ Lumbar spine } & Manual & 40 & 0.012 & 0.075 & \multirow[b]{2}{*}{0.719} \\
\hline & $\begin{array}{l}\text { Supervi- } \\
\text { sion }\end{array}$ & 40 & 0.018 & 0.060 & \\
\hline \multirow[b]{2}{*}{ Total femur } & Manual & 39 & -0.003 & 0.033 & \multirow[b]{2}{*}{0.442} \\
\hline & $\begin{array}{l}\text { Supervi- } \\
\text { sion }\end{array}$ & 40 & 0.003 & 0.029 & \\
\hline \multirow[b]{2}{*}{ Femoral neck } & Manual & 40 & -0.002 & 0.032 & \multirow[b]{2}{*}{0.714} \\
\hline & $\begin{array}{l}\text { Supervi- } \\
\text { sion }\end{array}$ & 40 & 0.001 & 0.038 & \\
\hline
\end{tabular}

† BMD- Bone Mineral Density 
Table 2: Summary measures of the variation in Bone Mineral Density (BMD) pre- and post therapy and 95\% Confidence Interval (CI).

\begin{tabular}{|c|c|c|c|c|c|}
\hline BMD $^{+}$ & Mean & $\begin{array}{c}\text { Standard } \\
\text { deviation }\end{array}$ & Minimum & Maximum & $\mathbf{9 5 \%}$ CI \\
\hline $\begin{array}{c}\text { Lumbar } \\
\text { spine }\end{array}$ & 0.014 & 0.068 & -0.109 & 0.321 & {$[-0.001 ; 0,029]$} \\
\hline Total femur & 0.000 & 0.031 & -0.089 & 0.101 & {$[-0.007 ; 0,007]$} \\
\hline $\begin{array}{c}\text { Femoral } \\
\text { neck }\end{array}$ & -0.001 & 0.035 & -0.153 & 0.118 & {$[-0.008 ; 0,007]$} \\
\hline
\end{tabular}

† BMD- bone mineral density

Table 3: Comparison between the evolutions of Bone Mineral Density (BMD) according to prior physical activity by the Mann-Whitney test

\begin{tabular}{|c|c|c|c|c|c|}
\hline BMD & $\begin{array}{c}\text { Prior physical } \\
\text { activity }\end{array}$ & Mean & SD & $\mathbf{9 5 \%}$ CI & P \\
\hline \multirow{2}{*}{$\begin{array}{c}\text { Lumbar } \\
\text { spine }\end{array}$} & Yes & 0.027 & 0.083 & $\begin{array}{c}{[-0.011 ;} \\
0.066]\end{array}$ & \multirow{2}{*}{0.102} \\
\cline { 2 - 5 } & No & 0.009 & 0.062 & $\begin{array}{c}{[-0.006 ;} \\
0.025]\end{array}$ & \\
\hline \multirow{2}{*}{ Total femur } & Yes & 0.004 & 0.024 & $\begin{array}{c}{[-0.006 ;} \\
0.016]\end{array}$ & \multirow{2}{*}{0.228} \\
\cline { 2 - 5 } & No & -0.001 & 0.033 & $\begin{array}{c}{[-0.010 ;} \\
0.007]\end{array}$ & \\
\hline \multirow{2}{*}{$\begin{array}{c}\text { Femoral } \\
\text { neck }\end{array}$} & Yes & 0.002 & 0.025 & $\begin{array}{c}{[-0.009 ;} \\
0.013]\end{array}$ & \multirow{2}{*}{0.670} \\
\cline { 2 - 5 } & No & -0.001 & 0.038 & $\begin{array}{c}{[-0.011 ;} \\
0.008]\end{array}$ & \\
\hline
\end{tabular}

Table 4: Correlation between age, age at menarche, age at menopause, weight and height with the evolutions of the lumbar vertebrae, total hip and femoral neck Bone Mineral Density (BMD) by Pearson correlation.

\begin{tabular}{|c|c|c|c|}
\hline Variables & $\begin{array}{c}\text { BMD } \\
\text { (lumbar spine) }\end{array}$ & $\begin{array}{c}\text { BMD } \\
\text { (total femur) }\end{array}$ & $\begin{array}{c}\text { BMD } \\
\text { (femoral neck) }\end{array}$ \\
\hline Age & 0.018 & -0.169 & -0.006 \\
\hline P value & 0.874 & 0.136 & 0.959 \\
\hline $\begin{array}{c}\text { Age at } \\
\text { menarche }\end{array}$ & 0.062 & -0.037 & -0.15 \\
\hline P value & 0.588 & 0.745 & 0.184 \\
\hline $\begin{array}{c}\text { Age at } \\
\text { menopause }\end{array}$ & -0.203 & -0.139 & -0.018 \\
\hline P value & 0.07 & 0.221 & 0.875 \\
\hline Weight & 0.135 & 0.247 & 0.12 \\
\hline P value & 0.232 & 0.028 & 0.288 \\
\hline Height & 0.012 & 0.305 & 0.138 \\
\hline P value & 0.918 & 0.006 & 0,223 \\
\hline
\end{tabular}

interviewed by telephone and most of them (80\%) responded. During their final telephone interview, they reported that they were taking daily walks, felt very well, performing the exercises designated from the instruction manual, they did not have any difficulty executing the exercises, and no longer felt anybody pain. They also reported their intention to continue with the home exercises until the final BMD was executed at the end of the study.

\section{Discussion}

With the ageing of the population, osteoporosis has become the most common disease of bone metabolism, affecting around 200 million people worldwide, and it is currently one of the main causes of deterioration in quality of life, morbidity and mortality among women after menopause $[10,18]$. It is estimated that $30 \%$ of postmenopausal women have osteoporosis [11]. Mortality associated with osteoporosis is especially due to the complications caused by osteoporotic fractures that trigger imbalance in the cardiorespiratory, vascular, and renal systems, and can lead to death in approximately $25 \%$ of patients [19-21]. Spinal, hip and distal-third forearm fractures are not the only ones related to osteoporosis and to ageing but fractures of the humerus, ankle, pelvis, and ribs are also associated with age and with osteoporosis [22]. In fact, at the beginning of this study, carried out with elderly women without suspicion of osteoporosis, we found $83.2 \%$ with some reduction in bone mass and $24.4 \%$ of the patients already had osteoporosis, revealing a high prevalence of the disease. Osteoporosis develops silently, and there were no complaints relating to the disease in $19 \%$ and $15 \%$ of the participants in the manual and supervision group, respectively.

The prevalence of osteopenia and osteoporosis hasshown in Brazilian studies, to be widely variable. In the cohort of the

Table 5: Comparison of findings of Bone Mineral Density (BMD) before and after intervention in the Manual group by means of the McNemar test.

\begin{tabular}{|c|c|c|c|c|c|}
\hline \multirow{2}{*}{ Conclusion (pre) } & \multicolumn{4}{|c|}{ Conclusion (post) } & \multirow{2}{*}{ Total } \\
\cline { 3 - 6 } & & Normal & $\begin{array}{c}\text { Low bone } \\
\text { mass }\end{array}$ & Osteoporosis & \\
\hline \multirow{2}{*}{ Normal } & $\mathrm{N}$ & 4 & 4 & 0 & 8 \\
\cline { 2 - 6 } & $\%$ & $9.5 \%$ & $9.5 \%$ & $0.0 \%$ & $19.0 \%$ \\
\hline \multirow{2}{*}{ Low bone mass } & $\mathrm{n}$ & 1 & 19 & 4 & 24 \\
\cline { 2 - 6 } & $\%$ & $2.4 \%$ & $45.2 \%$ & $9.5 \%$ & $57.1 \%$ \\
\hline \multirow{2}{*}{ Osteoporosis } & $\mathrm{n}$ & 1 & 0 & 9 & 10 \\
\cline { 2 - 6 } & $\%$ & $2.4 \%$ & $0.0 \%$ & $21.4 \%$ & $23.8 \%$ \\
\hline \multirow{2}{*}{ Total } & $\mathrm{n}$ & 6 & 23 & 13 & 42 \\
\cline { 2 - 6 } & $\%$ & $14.3 \%$ & $54.8 \%$ & $31.0 \%$ & $100.0 \%$ \\
\hline
\end{tabular}

$\mathrm{P}=0.079$ (McNemar test); $\mathrm{n}=$ number of women.

Table 6: Comparison of findings of Bone Mineral Density (BMD) before and after intervention in the Supervision group by means of the McNemar test.

\begin{tabular}{|c|c|c|c|c|c|}
\hline \multirow{2}{*}{ Conclusion (pre) } & \multicolumn{4}{|c|}{ Conclusion (post) } & \multirow{2}{*}{ Total } \\
\cline { 2 - 6 } & & Normal & Low bone mass & $\begin{array}{c}\text { Osteopo- } \\
\text { rosis }\end{array}$ & \\
\hline \multirow{2}{*}{ Normal } & $\mathrm{n}$ & 5 & 1 & 0 & 6 \\
\cline { 2 - 6 } & $\%$ & $12.5 \%$ & $2.5 \%$ & $0.0 \%$ & $15.0 \%$ \\
\hline \multirow{2}{*}{ Low bone mass } & $\mathrm{n}$ & 11 & 12 & 1 & 24 \\
\cline { 2 - 6 } & $\%$ & $27.5 \%$ & $30.0 \%$ & $2.5 \%$ & $60.0 \%$ \\
\hline \multirow{2}{*}{ Osteoporosis } & $\mathrm{n}$ & 3 & 4 & 3 & 10 \\
\cline { 2 - 6 } & $\%$ & $7.5 \%$ & $10.0 \%$ & $7.5 \%$ & $25.0 \%$ \\
\hline \multirow{2}{*}{ Total } & $\mathrm{n}$ & 19 & 17 & 4 & 40 \\
\cline { 2 - 6 } & $\%$ & $47.5 \%$ & $42.5 \%$ & $10.0 \%$ & $100.0 \%$ \\
\hline
\end{tabular}

$\mathrm{P}=0.004$ (McNemar test); $\mathrm{n}=$ number of women. 
Osteoporosis Study in São Paulo (SAPOS), Pinheiro and Eis [19] found osteoporosis in 33\% of the women, according to the findings of the bone densitometry, and $11.5 \%$ with a history of fracture due to bone fragility, mainly vertebral (86\%) [23]. In Brazil, it is estimated that 10 million individuals are affected by osteoporosis [5].

Our findings are discordant with those obtained by Siqueira et al. in 2009 [24], who observed a positive association between osteoporosis and the age of women. In 2005, Vu etal. [18] reported in a group of Vietnamese women, that osteoporosis increases with age; on the other hand, we did not find a correlation between age and BMD in this study or a plausible explanation for this fact.

In this study, contrary to similar research, the age of a woman at menarche bore no correlation with the densitometry; neither of these results is in agreement with those observed by Zehnacker and Bernis-Dougherty [10], who reported that postmenopausal osteoporosis usually affects women after 15 to 20 years of menopause. They observed that greater bone loss occurs around 5 to 7 years after menopause. The loss of bone mass resulting from the interruption of ovarian activity occurs in all the main regions of the skeleton. However, during the first years of the postmenopausal stage, the proportion of bone lost from the peripheral skeleton (predominantly cortical bone) differs from loss in the axial skeleton (predominantly trabecular bone). What was seen in this study is that the time of menopause onset bore no direct correlation with the BMD tests of the lumbar spine, total femur, and femoral neck.

Since 1994, the World Health Organization (WHO) has supported the position that the bone densitometry performed by dual energy $\mathrm{x}$-ray is the gold standard for diagnosing osteoporosis. Since that time, the number of densitometries have grown considerably [25]. The International Society for Clinical Densitometry (ISCD) recommends the use of the BMD value, the standard deviation in relation to the young adult (T-score), and the use of WHO standards only for postmenopausal women and men of 50 years age or over [25]. With these standards, it becomes possible to diagnose and treat osteoporosis, when there is a bone density greater than or equal to two standard deviations below the mean expected in the healthy population from the same age bracket [8]. Although the importance of this test is widely publicized, we verified that only $58.8 \%$ of the patients had performed a BMD test before the study. A total of $58.8 \%$ of the women presented low bone mass on the first densitometry, data that coincided with the findings of Steiner et al. [10], who subsumed the early diagnosis in the risk groups as a means of decreasing the morbidity and mortality resulting from the disease and ultimately, reducing public health costs. Drug therapy, such as hormone replacement, calcitonin, bisphosphonates, and estrogen receptor modulators is expensive and can have serious side effects. Changes in lifestyle with adequate dietary calcium intake, smoking cessation, moderate alcohol consumption, resistance exercises and load-bearing exercises are better alternatives or adjunctive treatments $[10,11]$. Physical activity is important for osteoporosis treatment and prevention. Although the benefits of exercise for general health leave no room for doubt, there is not yet any evidence that exercise alone prevents the negative effects of hypo-estrogenism. Plastic deformation occurs during physical activity, with the contraction of the muscles, and bones interpret this deformation as neo-formation stimulus. In this study, exercise provided maintenance of BMD. Physical activities are currently among the main interventional strategies for disease prevention, particularly as they act in the prevention of several non-transmissible diseases, such as osteoporosis [26]. Not withstanding their importance and widespread disclosure, we found that $74.4 \%$ of the women did not practice physical activity prior to the start of this study.

We agree with Barbosa et al. in 2000 [27], who argued that regular physical activity appears to have a positive effect on various physiological functions and in terms of osteoporosis prevention. Exercise that requires weight bearing has proven more effective than activities in a seated position $[17,28]$.

A form of physical activity that has been studied extensively in elderly individuals in the past decade is resistance training or strength training. According to Simão [29], strength training is used to improve performance, prevent injuries, and to improve general fitness, and increases the size and tropism of muscles in rehabilitation programs; as a response to physical and mechanical stress, there is bone remodeling [30], which suggests a direct correlation between physical load and bone formation. Thus, muscle activity can be considered effective in the maintenance of BMD, if the strength developed reaches the effective minimum tension. Lima and Fontana [31], warn that, besides mechanical load, osteogenic stimulus depends on the number of repetitions (frequency and duration), and the architecture of the bone mass present. Another beneficial effect depends on the serum levels of calcium and estrogens. Osteogenic stimuli provided by weightbearing exercises indicate the importance of lifestyle factors that can be used to prevent bone loss. This appears to coincide with our results, which indicate that over a short period of time, maintenance can be observed as well as the tendency for improvement in BMD values (Tables 1,2 ) during the 9 months of exercise.

We agree, however, that little is known about the practice of physical activity and about the patterns of behavior of this practice in postmenopausal women [32]. This hinders the work of health professionals with respect to counseling about the importance of adequate physical activities of women in this age bracket. Nevertheless, we noticed good adherence to exercise prescription, in both groups, under supervision and at a distance.

Although it is known that physical activity is important to maintain bone health in the postmenopausal years, this activity by itself does not protect women against osteoporosis [31]. It is important to encourage and counsel women in the practice of physical activity compatible with their physical condition. There have been documented bone mass gains after one to two years of intense physical activity. The same results could not be seen in this study. We did not observe any statistically significant differences between the densitometry values after the interventions, possibly due to the short follow-up time. However, in the results of the BMDs, we were able to note that there was 
a statistically significant improvement in the supervision group and at least maintenance in the manual group.

Despite a training period that was almost twice as long, we did not find statistical evidence of gain in BMD like that found by Simão [29], who documented an improvement of 38\% in the BMD of the radius after five months of physical activity.

In the systematic review conducted by Zehnacker and BemisDougherty [10], they observed that some studies reported that the limited effects on BMD were due to the performance of physical activity in just one or two sessions a week. The same problem could have interfered in our results. This also applies to the duration of the exercise period, which should have been at least one year in order to allow the changes to be noticed in the BMD of the femoral neck and trochanter. Bones are a dynamic tissue that undergoes a continuous process of formation and reabsorption, and responds to constant changes of mechanical forces that meet at its surface. Thus we believe that weight-bearing training should be performed at least two to three times a week for a period of 12 to 18 months, in order to guarantee the outcome of the training as it relates to BMD. The outcome can then be measured in the bone equilibrium status. The protective effect occurs even in the long term.Physical activity in adolescence protects against osteoporosis in adult life [24]. Zehnacker and Bernis-Dougherty [10], reported that, eight years after the end of a two-year exercise program, the exercise group had suffered a loss of BMD, but this loss was less significant in the exercise group than in the control group, which realized stretching at home. Although there are considerable publications related to the role of exercise and its positive effects on BMD, a regiment of specific exercises remains necessary in order to reduce the risks or effects of osteoporosis in postmenopausal women. The physiotherapy interventions reported in the literature still focus on postural care, balance training, and aerobic exercises designed to decrease risk factors and the consequences associated with osteoporosis, even though there is evidence indicating that weight-bearing exercises increase and maintain BMD. Moreover, a more specific exercise regiment is required for patients, especially risk groups, such as postmenopausal women, in order to obtain the benefits of a welldesigned physiotherapy program.

Physical activity is vital for the lifetime maintenance of bone health, and is an important factor in osteoporosis prevention, reduction of falls, and a decrease in the risk of hip fractures [31-34]. An alarming increase in the prevalence of osteoporosis apparently expresses the need for a more active lifestyle among people of all ages. The main benefits of regular physical activity have been well documented. There needs to be a change in politics and a change in the interventions provided by health professionals in order to best determine how to promote physical activity in the general population. National and local policies should be developed, in addition to planned campaigns to improve public awareness of the need for an active lifestyle, accompanied by well-designed programs which can make physical activity easier and more gratifying [35].
Exercise provides benefit to health and a specific exercise regiment is necessary [36]. The theoretical basis for an exercise program is the physiology of the energy metabolism and the response of various systems to different types of training. As presented in other studies [31,35-37] ,this survey demonstrated the benefits for women, as well as the maintenance of bone mineral density.

\section{Conclusion}

Physical exercise performed with or without supervision promoted the maintenance of BMD in postmenopausal women, who would have otherwise had a tendency to present bone mass loss.

\section{Acknowledgments}

We would like to express our special appreciation and thanks to Dr. Shlomo Lewin.

\section{Sources of funding}

Coordenação de Aperfeiçoamento de Pessoal de Nível Superior (Capes).

\section{References}

1. Jones S, Johansen A, Brennan J, Butler J, Lyons RA. The effect of socio-economic deprivation on fracture incidence in the United Kingdom. Osteoporos Int. 2004; 15(7): 520-524.

2. Frazão P, Naveira M. Prevalência de osteoporose: uma revisão crítica. Revista Brasileira de Epidemiologia. 2006; 9(2): 206-214.

3. Going S, Lohman T, Houtkooper L, Metcalfe L, Flint-Wagner H, Blew $\mathrm{R}$, et al. Effects of exercise on bone mineral density in calcium-replete postmenopausal women with and without hormone replacement therapy. Osteoporos Int. 2003; 14(8): 637-643.

4. Lin JT, Lane JM. Osteoporosis: a review. Clin Orthop Relat Res. 2004; (425): 126-34.

5. Sen SS, Rives VP, Messina OD, Morales-Torres J, Riera G, AnguloSolimano JM et al. A risk assessment tool (OsteoRisk) for identifying Latin American women with osteoporosis. J Gen Intern Med. 2005; 20(3): 245-250

6. Guadalupe-Grau A, Fuentes T, Guerra B, Calbet JA. Exercise and bone mass in adults. Sports Med. 2009; 39(6): 439-468.

7. Russo LAT. Osteoporose pós-menopausa: opções terapêuticas. Arq Bras Endocrinol Metab. 2001; 45(4).

8. Gracia CR, Sammel MD, Freeman EW, Lin H, Langan E, Kapoor S, et al. Defining menopause status: creation of a new definition to identify the early changes of the menopausal transition. Menopause. 2005; 12(2): $128-135$.

9. Steiner ML, Fernandes CE, Strufaldi R, Azevedo LH, Stephan C, Pompei LM, et al. Accuracy study on "Osteorisk": a new osteoporosis screening clinical tool for women over 50 years old. Sao Paulo Med J. 2008; 126(1): 23-28.

10.Zehnacker CH, Bemis-Dougherty A. Effect of weighted exercises on bone mineral density in post menopausal women: A systematic review. J Geriatr Phys Ther. 2007; 30(2): 79-88.

11. Terrio K, Auld GW. Osteoporosis knowledge, calcium intake, and weight-bearing physical activity in three age groups of women. J Community Health. 2002; 27(5): 307-320. 
12. Carvalho CMRG, Fonseca CCC, Pedrosa JI. Educação para a saúde em osteoporose com idosos de um programa universitário: repercussões. Cad Saúde Pública. 2004; 20(3): 719-726.

13. Britton A, Shipley M, Singh-Manoux A, Marmot MG. Successful aging: the contribution of early-life and midlife risk factors. J Am Geriatr Soc. 2008; 56(6): 1098-1105.

14. Marshall D, Johnell O, Wedel H. Meta-analysis of how well measures of bone mineral density predict occurrence of osteoporotic fractures. BMJ. 1996; 312(7041): 1254-1259.

15. Kanis JA, Gluer CC. An update on the diagnosis and assessment of osteoporosis with densitometry. Committee of Scientific Advisors, International Osteoporosis Foundation. Osteoporos Int. 2000; 11(3): 192-202.

16. Leib ES, Lewiecki EM, Binkley N, Hamdy RC, International Society for Clinical Densitometry. Official positions of the International Society for Clinical Densitometry. J Clin Densitom. 2004; 7(1): 1-6.

17. Jovine MS, Buchalla CM, Santarém EMM, Santarém JM, Aldrighi JM. Efeito do treinamento resistido sobre a osteoporose após a menopausa: estudo de atualização [Effect of resistance training on postmenopausal osteoporosis: update]. Rev Bras Epidemiol. 2006; 9(4): 493-505.

18. Vu TT, Nguyen CK, Nguyen TL, Le Bach Ma, DucSon NguyenTrung Le, et al. Determining the prevalence of osteoporosis and related factors using quantitative ultrasound in Vietnamese adult women. Am J Epidemiol. 2005; 161(9): 824-830.

19. Pinheiro MM, Castro CM, Szejnfeld VL. Low femoral bone mineral density and quantitative ultrasound are risk factors for new osteoporotic fracture and total and cardiovascular mortality: a 5-year population-based study of Brazilian elderly women. J Gerontol A Biol Sci Med Sci. 2006; 61(2): 196-203.

20.Vidal EI, Coeli CM, Pinheiro RS, Camargo KR. Mortality within 1 year after hip fracture surgical repair in the elderly according to postoperative period: a probabilistic record linkage study in Brazil. Osteoporosis Int. 2006; 17(10): 1569-76.

21. Fortes EM, Raffaelli MP, Bracco OL, Takata ET, Reis FB, et al. [High morbid-mortability and reduced level of osteoporosis diagnosis among elderly people who had hip fractures in São Paulo City]. Arq Bras Endocrinol Metabol. 2008; 52(7): 1106-1114.

22. Ballard JE, Wallace LS, Holiday DB, Herron C, Harrington LL, Mobbs $\mathrm{KC}$, et al. Evaluation of differences in bone-mineral density in 51 men age 65-93 years: a cross-sectional study. Journal of Aging and Physical Activity. 2003; 11(4): 470-486.

23. Pinheiro MM, Eis SR. [Epidemiology of osteoporotic fractures in Brazil what we have and what we need (review)]. Arq Bras Endocrinol Metab. 2010; 54(2): 164-170.

24.Siqueira FV, Facchini LA, Azevedo MR, Reichert FF, Bastos JP, Silva MC, et al. [Physical activity practice in adolescence and prevalence of osteoporosis in adulthood]. Rev Bras Med Esporte. 2009; 15(1): 2730.

25.Sampaio Netto O, Coutinho LOL, Souza DC. [Analysis of the new classification of bone densitometry reports]. Radiol Bras. 2007; 40(1): 23-25.

26.Florindo AA, Latorre MRDO, Tanaka T, Jaime PC, Zerbini CAF. Atividade física habitual e sua relação com a densidade mineral óssea em homens adultos e idosos. Revista Brasileira de Atividade Física \& Saúde. 2000; 5(1): 22-34.

27. Barbosa AR, Santarém JM, Jacob Filho W, Marucci MFN. Efeitos de um programa de treinamento contra resistência sobre a força muscular de mulheres idosas. Revista Brasileira de Atividade Física \& Saúde. 2000; 5(3): 12-20.

28.Shephard RJ. Envelhecimento, atividade física e saúde. São Paulo: Phorte; 2003.

29.Simão R. Fundamentos fisiológicos para o treinamento de força e potência. Phorte editora; 2003.

30. Nunes JF. Atividade física e osteoporose. Londrina Midiograf; 2001.

31.Lima SMT, Fontana CM. Atividade física com um dos aspectos preventivos da osteoporose. Arq Ciências Saúde UNIPAR. 2000; 4(2): 129-34.

32.Silva RB, Costa-Paiva L, Pinto Neto AM, Braga AA, Morais SS. [Habitual physical activity and cardiovascular risk in post menopause]. Rev Assoc Med Bras. 2006; 52(4): 242-246.

33. Pinheiro MM, Ciconelli RM, Martini LA, Ferraz MB. Clinical risk factors for osteoporotic fractures in Brazilian women and men: the Brazilian Osteoporosis Study (BRAZOS). Osteoporos Int. 2009; 20(3): 399-408.

34.Pinheiro MM, Reis Neto ET, Machado FS, Omura F, Yang JH, Szejnfeld $\mathrm{J}$, et al. [Risk factors for osteoporotic fractures and low bone density in pre and postmenopausal women]. Rev Saude Publica. 2010; 44(3): 479-485.

35. Kai MC, Anderson M, Lau EM. Exercise interventions: defusing the world's osteoporosis time bomb. Bull World Health Organ. 2003; 81(11): 827-830.

36. Ashe MC, Khan KM. Exercise prescription. J Am Acad Orthop Surg. 2004; 12(1): 21-27.

37. Mandine MJ, Michel JP. Atividade física para adultos com mais de 55 anos. São Paulo: Manole; 2001. 